\title{
How to Sustain PBS Without Magic in Forensic Psychiatric Facilities \& Community Settings
}

\author{
Rhiannon Evans \\ Missouri Department of Mental Health \\ Lucas Evans \\ Missouri Department of Mental Health \\ Teresa Rodgers \\ Missouri Department of Mental Health
}

\begin{abstract}
A barrier to successful implementation of behavior change strategies may be a chronic staffing crisis leading to poor staffing ratios, competing job tasks, and burnout. The staffing crisis often results in environments in which challenging behaviors receive more interactions. A system oriented approach embedding positive behavior strategies into existing processes helps improve and sustain implementation without magic. This multi-level coaching process demonstrated significant reduction in problem behavior in seven applied settings. Furthermore, participants in the intervention reported increased job satisfaction, including a better relationship with individuals supported and with the supervisors delivering regular onsite feedback.
\end{abstract}

Keywords: implementation, sustainability, supervision, positive behavior interventions and support, relationships, treatment fidelity, system change, organization leadership

\section{INTRODUCTION}

In the human service field, savvy staff development professionals know that just training staff without follow up coaching, feedback, and supervisor actions will be a false promise (Joyce and Showers, 2002). However, many supervisors and administrators continue to rely on a one off staff training as a panacea for problems that occur in the field. Even though service providers are required to ensure that staff receive some type of new employee orientation and some regular training as part of the licensure and funding process, problems with staff follow through and skill deficits plague the industry. In addition, these requirements rarely include competency based training or ensuring that the skills are utilized. This standard of training would hardly be accepted in other important fields; medical professionals, airline pilots, and beauticians are required to meet ongoing training and competency standards. Yet, human services staff who serve the most vulnerable populations are paid low wages, given minimal training and are required to have expertise in a wide range of skills from food service and nutrition to teaching, medication management and recreation (United States Department of Health and Human Services, 2018). Supervisors and administrators struggle to meet service standards and try to impact staff performance 
using ineffective methods. The cost of these ineffective methods for staff training is great. It is estimated that the annual staff turnover rate in human services is approximately $45 \%$ and that the average expense of onboarding a new employee is between $\$ 2,500$ to $\$ 5,000$ (United States Department of Health and Human Services, 2018).

With their wide array of responsibilities staff often do not have the time or ability to engage in meaningful and nurturing ways with the people they are serving. Yet, positive and nurturing relationships are very important for individuals receiving care (Holt-Lunstad,_2018). Individuals residing in institutions live in rigid environments with minimal social interaction or control over their daily life (Ross, 2012). Individuals living in group homes and other residential community settings that require care from direct support professionals (DSPs) also have limited access to friends or family, and staff or peers are the primary source of social interactions (Apel \& Diller, 2017). In addition, the lack of engaging and nurturing relationships aggravates or creates challenging behaviors which make the DSP job even more difficult (United States Department of Health and Human Services 2018). Frequently in these environments where attention is a scarce resource, displays of problem behavior are guaranteed to pay off; whereas, more desirable behavior does not and staff spend most of their energy responding to crises. Therefore, the frequency of the challenging behavior increases (Luiselli, Dunn, \& Pace, 2005; Luiselli, 2012). As a result the ratio of positive to negative interactions is lower. Higher ratios of positive to negative interactions are important for developing meaningful relationships (Flora, 2000; Gottman, 1998).

One way to help increase the ratio of positive to negative interactions is to teach staff how to respond in different situations. "Tools for Positive Behavior Change" (Stoutimore, Williams, Neff \& Foster, 2008) is a behavior analytically-based curriculum that teaches caregivers to build nurturing relationships and promotes emotional regulation. It has been shown to reduce the total frequency of restrictive procedures when implemented at a locked residential facility serving youth ages 13-17 years old (Crosland et al., 2008). In Missouri, Tools for Positive Behavior Change (also known as Tools of Choice) has been implemented statewide within community residential settings using a positive behavior intervention and supports (PBIS) approach, including the monitoring of treatment fidelity.

It is important to ensure that staff are able to use new skills as designed and that they do so on an ongoing basis, this is treatment fidelity. Research has demonstrated that high levels of treatment fidelity typically result in positive outcomes and that low levels of treatment fidelity often result in many negative outcomes (DiGennaro et al., 2005; DiGennaro et al., 2018). Preliminary intervention outcomes may fail to maintain because they are not implemented consistently or as originally designed even with intensive initial training (DiGennaro et al., 2005; McIntrye, et al., 2007). Often maintenance of intervention fidelity declines when the behavior analyst or program lead involvement fades. DiGennaro et al. (2018) suggested providing ongoing support in the form of monitoring, coaching with practice and reinforcement of staff behavior as a way to address this issue. Utilizing a PBIS approach by embedding the expectation for supervisors to observe and provide feedback to staff into routine activities throughout the day should improve intervention fidelity.

The promise and magic of the PBIS movement and organizational behavior management (OBM) is the ability to impact job performance and cultural practices through a systems approach. Creating the necessary culture change and consistent implementation of new practices through PBIS or OBM methods is, however, hard work. This cannot be accomplished with traditional one off didactic training or complicated policy directives. The systems approach requires the support of administration, supervisors and DSPs, with repeated modeling, practice and feedback. Training staff to increase positive interactions and build meaningful relationships using such a behavior skills training model, with infrastructure to support the new skills, can work like magic and have significant impact, reducing challenging behaviors and increasing skills and on the job satisfaction for staff.

This study is a report of the integration of systematic PBIS strategies to improve implementation fidelity in an institution based treatment program within a mid-western state forensic psychiatric hospital, and a state contracted residential independent supported living (ISL) provider. The programs adjusted existing supervisor and staff practices to increase opportunities for routine meaningful attention (see procedures) throughout the day. The authors evaluated the outcomes of these programmatic changes, 
specifically the relation of supervision fidelity and DSP fidelity. That is, when supervisors provide active supervision, do DSPs interact more often with individuals supported? Does this change in supervisor behavior also result in less problem behavior and an increase in quality of life?

\section{METHOD}

\section{Participants and Settings}

The program changes were implemented across five units at an inpatient, 341 bed, forensic psychiatric hospital in Missouri. Two living units were maximum-security environments (B08 \& B09), two were medium-security environments (G01 \& G02), and one was a minimum-security environment (HF1). Each of these living units had approximately 28 individuals and 20 staff, for a total of approximately 140 individuals and 100 staff, who participated in the program. Participants included staff and residents of the New Outlook Program (NOP). NOP treats adults ranging in age from 18 to 82 years old with dual diagnosis of mental illness (primarily mood disorders or borderline personality disorder) and intellectual and developmental disabilities. Many of the individuals were admitted to the hospital for a crime and were found "not guilty by reason of mental defect or disorder" or "not able to proceed to court". Admissions also included "voluntary by guardian". These individuals were deemed a risk to themselves and others in the community. Staff were required to be 18 years or older to work in the minimum-security unit, and 21 years or older to work in higher security environments. DSPs worked 12hour shifts with rotating days off. Supervisors ranged from 21-70 years old and had varying degrees of education and experience with most of the supervisors being licensed mental health professionals with either a master's or doctorate degree.

Similar program changes were implemented in two ISLs housing adults with mental health concerns, and/or developmental disabilities. These ISLs consisted of a series of apartments designed for individuals to retain their independence in the community while still having access to staff support. One of the ISLs had single apartments and the other had two individuals per apartment. Participants at the community provider ISLs included approximately 14 staff and 38 residents participating in the state's Department of Mental Health, Division of Developmental Disabilities, Multi-Tiered-Systems-of-Support (MTSS) initiative. Contracted providers participating in the state's MTSS initiative are encouraged to develop several essential elements of PBIS including improving social interactions, action planning, and outcome data review. DSPs working in the ISLs were required to be 18 years or older, and often worked 12-hour shifts. Supervisors ranged from 38-47 years old with bachelor's degrees and varying levels of experience.

In both settings the focus was on staff working from the hours of 7:10am to 7:10pm because DSPs on this shift could be observed within the supervisor's normal work hours which reduced some of the response effort. Additionally, individuals typically slept in the evening which limited opportunities for meaningful interactions.

Trainers for the forensic psychiatric facility settings included the first and second author as well as behavior technicians employed by the facility. The programmatic changes first occurred with HF 1 under the oversite and direction of the second author while they were employed at the facility as a behavior analysis practicum student. The first author, also employed at the facility as a behavior analysis practicum student, continued implementation by providing oversight and direction with HF1 upon the second author's severance of employment with the facility. The first author extended the programmatic changes to the other four settings at the facility and provided oversite, direction, and training for both ISL settings as an unpaid external consultant to the community provider.

\section{Measurement}

Supervisors completed observations to assess DSP implementation fidelity. These observations by the supervisors lasted an average of 10-minutes and were conducted in person. Supervisors would mark a "Y" if staff required teaching, or an "N" if they did not (See Appendix 1). In the forensic setting supervisor fidelity was assessed using supervisory check sheets (See Appendix 2) to determine whether observations were completed as designed. Fourteen supervisory checks per week were scheduled for each setting. 
Feedback was given to DSPs following each observation. Supervisors continued in training sessions until they met a criteria of $90 \%$ agreement with the trainer on whether DSPs required additional teaching. Inter-observer agreement (IOA) was calculated by taking the total number of agreed upon scores divided by the total number of observations. For both forensic and community settings the supervisors were observed for $15 \%$ of their observations by trainers. Trainers delivered feedback to supervisors following each observation. Supervisors maintained an average of $81.6 \%$ reliability.

To approximate a count of challenging behaviors, the state of Missouri's incident reports event management tracking system was utilized. This is an electronic system for reporting incidents that involve seriously challenging behavior. Incident reports indicate what categories of seriously challenging behavior were present in addition to a narrative of the incident. Incident reports involving the following categories of challenging behaviors were aggregated by the first author, across each living unit: self-harm, physical aggression, and property destruction. The number of incident reports were coded, summed and tabulated electronically.

\section{Procedures}

At the forensic psychiatric facility changes were made to an existing routine hospital safety procedure (face-checks) in which DSPs located and identified each client every 15-minutes, 24 hours a day. The revised process included the addition of brief positive interaction (See Appendix 3) with each client. At the community ISLs changes were made to add meaningful interactions (See Appendix 3) to existing typical job duties such as medication administration, assisting individuals with household chores, checking in/out with them when they leave or return home, and periodically during leisure activities or free time throughout the day. A team of supervisors employed by each facility was trained by the first and second author to complete supervisory checks by collecting data daily to indicate if staff implemented the intervention correctly or not (See Appendix 1), and how to deliver feedback to DSPs (See Appendix 4). Each setting had a different team of supervisors.

In both the forensic and community settings DSPs and supervisors were trained in small groups. Each step was discussed individually and examples and non-examples were given. Trainers modeled the behavior for the group. Staff were then asked to model the steps presented in a role-play. The average training session time was 45-60 minutes.

To help further embed the program at the facility, the first author worked with administration to write the program into the NOP staff manual which functioned as program policy. The first author also instituted a weekly email that went out to all of the staff participating in the program at the forensic psychiatric facility, including the executive director of the facility and other administrative members of the team. This email included the completed supervisory observation forms (See Appendix 2) from each participating unit. This data was also posted on each unit's announcement board and discussed at biweekly team meetings. In addition, all teams that completed $80 \%$ or more checks four weeks in a row won a pizza party. In the community ISL settings the first author embedded the program into the MTSS initiative which already includes once a month meetings to discuss implementation progress with supervisors and key members of administration. A slight modification was made to also include biweekly emails to the director of the MTSS program to highlight supervisory check completion. Supervisors who completed their assigned observations chose to earn slushies from a local fast-food restaurant. 


\section{RESULTS}

FIGURE 1

IMPLEMENTATION FIDELITY CHANGE FOLLOWING SYSTEMS APPROACH

Percent Increase of Implementation Fidelity Following Systems

Intervention

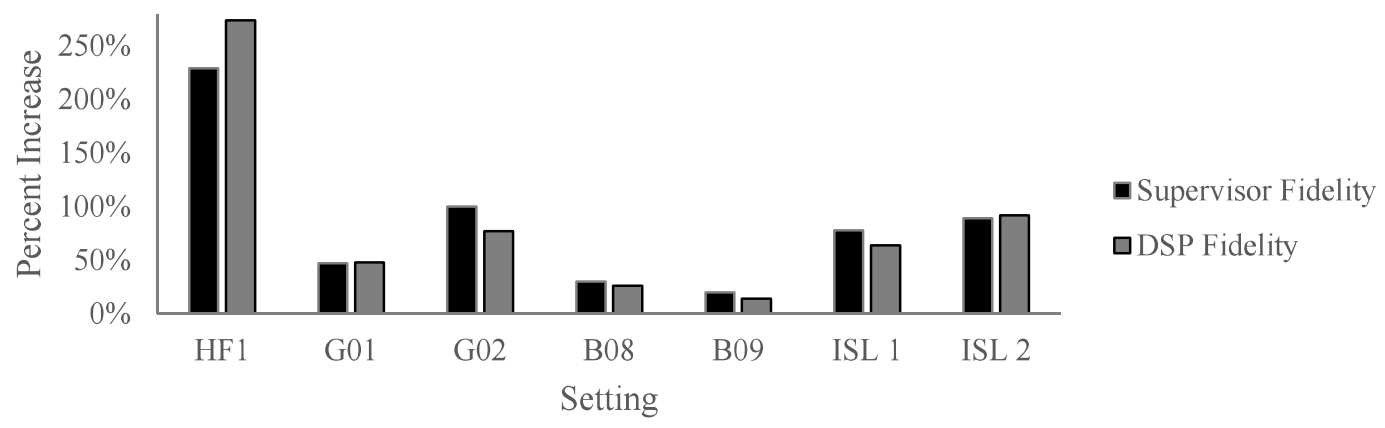

FIGURE 2

THE PERCENT REDUCTION OF ALL BEHAVIORAL INCIDENTS ACROSS SETTINGS

Percent Reduction of Behavioral Incidents Across Settings

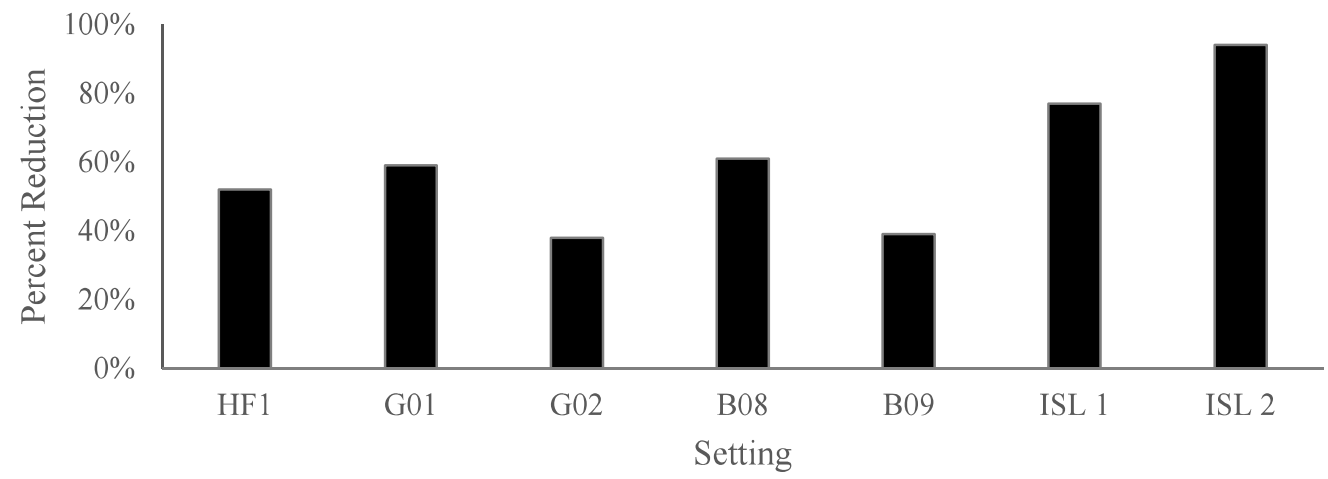




\section{FIGURE 3 \\ THE PERCENT REDUCTION OF PHYSICAL ALTERCATIONS WITH STAFF ACROSS SETTINGS}

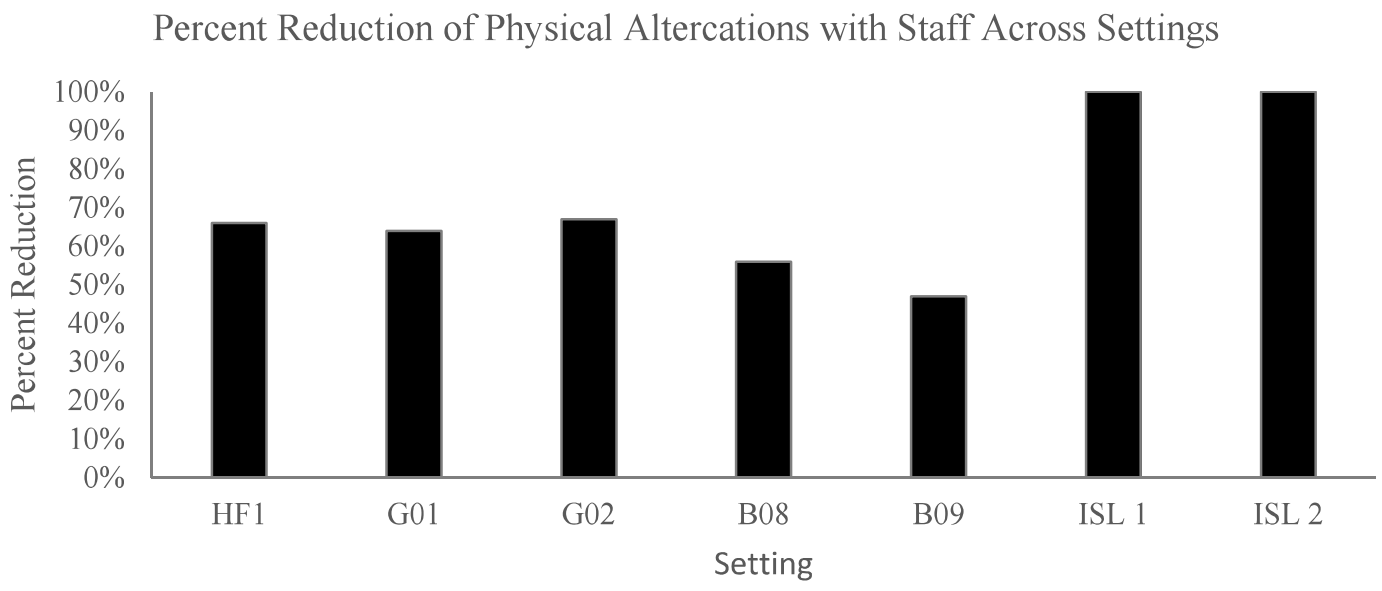

Each setting that implemented the programmatic changes had an increase in both supervisor and DSP fidelity (See Figure 1), with an average increase of $85 \%$ for both supervisors and DSPs. Furthermore, there was a significant decrease of incident reports involving challenging behavior in each setting (See Figure $2 \&$ Appendix 5), with an average reduction of approximately $60 \%$. Since the procedures also had the goal of improving the relationship between staff and the individuals they served, the frequency of physical altercations directed toward staff was analyzed. This revealed a slightly more impressive reduction in incidents, with an average reduction of $71 \%$ (See Figure $3 \&$ Appendix 6 ). Change in fidelity was calculated by subtracting the fidelity score after implementing the programmatic changes by the fidelity score during baseline. That number was then divided by the fidelity score during baseline. Change in behavioral incidents was calculated by subtracting the number of incidents after the programmatic changes from the number of incidents before the changes were implemented. That number was then divided by the number of incidents during baseline to give the percent of change in incidents. Equal time periods were used for analysis of incidents before and after the changes occurred (See Appendix 7).

Social validity surveys were conducted four weeks after the first author ceased involvement with the PBIS program. DSPs at all settings rated their supervisors as more competent, understanding, and approachable, said their relationship with individuals supported seemed stronger; and, they said the program was easy to do. Supervisors at all of the settings said their relationship with DSPs was stronger while implementing the program as designed. Supervisors at the ISLs said the program was easy to do. However, supervisors at the forensic psychiatric settings reported it was difficult to allocate time to supervise staff doing the face checks.

\section{DISCUSSION}

The procedures implemented by staff and supervisors in all settings were designed to be extensions or small modifications to existing job requirements. This had the advantage of not needing to redesign the environment and job duties or convince staff to use unfamiliar strategies. Including brief positive interactions during routine activities seemed to make sense to the participants, both staff and supervisors, and was reported as not too difficult or time consuming. Supervisors had significantly improved daily coaching and feedback of DSPs positive interactions (see Figure 1). After the initial training of the PBS curriculum, DSPs still were not regularly doing the skills in the natural care setting. However, after experiencing frequent coaching from supervisors, most DSPs were able to competently execute the procedure when observed in the natural care setting (see Figure 1). Finally, the involvement of 
organization leadership improved or maintained supervisor performance. Additionally, each setting had a significant reduction in serious behavioral incidents following implementation (see Figures $2 \& 3$ ). The results suggest that individuals may have no longer needed to resort to displays of challenging behavior to gain access to meaningful interactions. Since there were fewer incidents that required emergency procedures and overall less need for staff to intervene, it is likely that DSPs had more time for other job duties. DSPs also reported improved relationships with the individuals they supported, and overall the setting seemed to be safer. In summary, small changes in existing routine job duties of DSPs to include meaningful interactions with the individuals they supported had a huge positive impact; however, a systems approach that included frequent coaching from supervisors and regular review by organization leadership was necessary to make it happen. There are several implications for future programs.

\section{Any Additional Effort Impedes Implementation}

Frequent supervision in the form of ongoing observation and feedback is essential to sustaining implementation of PBIS procedures (DiGennaro et al., 2005; DiGennaro et al., 2018; McIntrye, et al., 2007). Many steps were taken to minimize the response effort of supervisors such as asking for as little as 15-minutes of each supervisor's work time each week and spreading the responsibility of supervision among a group of staff so no one person got stuck with a lot of extra work. However, in the forensic setting it proved difficult for supervisors to maintain consistent observations as they would often not make their goal of $80 \%$ completed observations for the week. There was a general lack of resources to support supervisors as there was only one trainer who had competing job duties and could only devote a portion of their time each week to this project. Supervisors were not located on the unit. Instead they would have to leave their office area, which was sometimes in another building, in order to implement the procedures and did not do this on a regular basis prior to the intervention. To address this barrier, the first author suggested supervisors conduct their observations and give DSPs feedback at a time in which they were already scheduled to be onsite for something else (e.g. prior to or directly following going to the unit to conduct therapy or a group activity). Supervisors said this helped make the program easier to follow, yet there were still some supervisors that refused to implement the program. To address this the procedures were written into policy, including the requirement of at least bi-weekly meetings to review progress with supervisors and program administrators. In addition, weekly emails highlighting supervisory check progress were introduced (see procedures). Future programs should incorporate performance expectations into policy and program administrators should take care to design opportunities for supervision around already established routines.

\section{Leadership Support Is Critical}

As mentioned above, part of the policy changes in the forensic setting to address supervisory checks that didn't meet goal was to include a bi-weekly meeting with program administrators and supervisors to review program data. While data shared was framed to focus on the positives of current progress, opportunities for improvement were readily apparent. Frequent meetings therefore allowed organizational leaders to recognize good performance, set goals for improvement, and stay current on the status of program implementation. In the residential setting, the agency was a member of the MTSS initiative. This initiative includes these regular review meetings and the community setting had made it a part of their normal process. This may help explain why the community setting didn't experience the same struggle to get supervisory checks completed. Future programs should consider involving multiple program administrators as part of a regular review and feedback process with supervisors.

\section{One Off Trainings Are Not Effective}

Another finding from the present program review included a positive, cumulative effect of repeated coaching of DSPs' implementation. The proportion of staff that needed re-training (i.e. did not complete all steps) steadily decreased over time. This was observed in all settings. Even though the initial trainings were competency-based staff did not use the trained skills in the natural situation. Only after DSPs were coached "on-the-job" were they successful in using the strategies. Program administers should devote 
training resources to on-going, on-the-job training in the form of coaching. Future programs should be designed with this as an essential feature of implementation.

\section{Limitations}

The authors conducted a retrospective analysis of existing programs to determine critical features. As such, no experimental controls were in place to mitigate the effects of confounding variables and implementation was not structured to compare systematic introduction and withdrawal. Only pre-program

and post-program evaluations were conducted. Such an analysis reveals results that should be viewed as indicators for further study in a more empirically-rigorous manner. However, results of the present analysis are consistent with findings by empirical research in implementation science (Fixsen, Naoom, Blase, Friedman \& Wallace, 2005). As such, the results can be viewed as the outcome of good implementation. Further research should continue to be conducted, and the authors feel the present work stands as further impetus for such research.

Indications of positive outcomes subsequent to good implementation were determined by analyzing reports entered into an event tracking system. Incident reports are a permanent product of staff behavior and may not represent the true count of behavior. Sometimes multiple instances of behaviors were included into a single incident report. It is also possible that challenging behavior was emitted and not recorded by staff. Nevertheless, we feel that the practical utility of using readily available incident report data outweighed any potential limitation in the examined settings. Future analyses should consider the feasibility of more sensitive outcome measures.

With limited availability of resources to increase the quality of life in restrictive environments, meaningful attention becomes a powerful tool. It is well known that enriched social environments have less problem behavior (Richman, Barnard-Brak, Grubb, Bosch \& Abby, 2015). Many times we have heard others in the field ask for magic fixes to complex problem situations. While we do not know of any such magic, our evaluation indicates that the systems approach provides a path for success. The PBIS system was effective at getting staff to implement PBIS skills, and behavioral incidents significantly reduced. Social validity data (see results) supports this conclusion. DSPs also indicated improved relationship with supervisors. Future research could examine whether effects can be replicated in similar settings where quality of life needs are difficult to address, such as correctional facilities, or retirement centers.

\section{REFERENCES}

Apel, A., \& Diller, J. (2017). Prison as punishment: A behavior-analytic evaluation of incarceration. Behavior Analyst, 40, 243-256.

Crosland, K. A., Cigales, M., Dunlap, G., Neff, B., Clark, H. B., Giddings, T., \& Blanco, A. (2008). Using staff training to decrease the use of restrictive procedures at two facilities for foster care children. Research on Social Work Practice, 18(5), 401-409.

DiGennaro, R F. D., Blackman, A. L., Erath, T. G., Brand, D., \& Novak, M. D. (2018). Guidelines for Using Behavioral Skills Training to Provide Teacher Support. Teaching Exceptional Children, 50(6), 373-380.

DiGennaro, F. D., Martens, B. K., \& McIntyre, L. L. (2005). Increasing treatment integrity through negative reinforcement: Effects on teacher and student behavior. School Psychology Review, 34, 220-231.

Fixsen, D., Naoom, S., Blase, K., Friedman, R., \& Wallace, F. (2005). Implementation Research: A Synthesis of the Literature. Tamps, FL: University of South Florida, Louis de la Parte Florida Mental Health Institute, National Implementation Research Network.

Flora, S. R. (2000). Praise's magic reinforcement ratio: Five to one gets the job done. The Behavior Analyst Today, 1(4), 64-69.

Gottman, J., Coan, J., Carrere, S., \& Swanson, C. (1998). Predicting marital happiness and stability from newlywed interactions. Journal of Marriage and the Family, 60(1), 5-22. 
Holt-Lunstad, J. (2018). Why Social Relationships Are Important for Physical Health: A Systems Approach to Understanding and Modifying Risk and Protection. Annual Review of Psychology. doi: 10.1146/annurev-psych-122216-011902.

Joyce, B. R., \& Showers, B. (2002). Student achievement through staff development (3rd ed.). Alexandria, VA: Association for Supervision \& Curriculum Development (ASCD).

Luiselli, J., Dunn, E., \& Pace, G. (2005). Antecedent assessment and intervention to reduce physical restraint (protective holding) of children and adolescents with acquired brain injury. Behavioral Interventions, 20, 51-65.

Luiselli, J. (2013). Descriptive analysis of a staff injury-reduction intervention in a human services setting for children and youth with intellectual and developmental disabilities. Behavior Modification, $37(5), 665-679$.

Luiselli, J. (2012). The handbook of high-risk challenging behaviors in people with intellectual and developmental disabilities. Baltimore, MD: Paul H. Brookes Publishing Co.

McIntyre, L. L., Gresham, F. M., DiGennaro, F. D., \& Reed, D. D. (2007). Treatment Integrity of schoolbased interventions with children in the Journal of Applied Behavior Analysis 1991-2005. Journal of Applied Behavior Analysis, 40(4), 659-672.

Richman, D. M., Barnard-Brak, L. B., Grubb, L., Bosch, A., \& Abby, L. (2015). Meta-analysis of noncontingent reinforcement effects on problem behavior. Journal of Applied Behavior Analysis, $48(1), 131-152$.

Ross, J. (2012). Why a jail or prison sentence is increasingly like a death sentence. Contemporary Justice Review, 15(3), 309-321.

Stoutimore, M.R., Williams, C. E., Neff, B., \& Foster, M. (2008). The Florida child welfare behavior analysis services program. Research on Social Work Practice, 18(5), 367-376.

United States Department of Health and Human Services. (2018). America's Direct Support Workforce Crisis: Effects on People with Intellectual Disabilities, Families, Communities and the U.S. Economy. Washington D.C.: President's Committee for People with Intellectual Disabilities.

\section{APPENDICES}

\section{APPENDIX 1 SUPERVISOR CHECK SHEET}

\begin{tabular}{|c|c|c|c|c|c|c|c|c|}
\hline \multicolumn{9}{|c|}{ Supervisor's Check Sheet } \\
\hline \multicolumn{9}{|c|}{$\begin{array}{l}\text { For each MORNING, and AFTERNOON period, } 1 \text { 15-minute period should be randomly observed to ensure that staff are engaging in meaningful interactions with clients. Initial in } \\
\text { the box to the left. Record the staff member observed, whether that staff member required additional teaching to successfully complete procedure, and if supervisor delivered the } \\
\text { training by modeling the correct action. Team Leader, Program Nurse Manager, FRSIII or ward RN are responsible for ensuring these checks are completed and the sheet is filled } \\
\text { out in entirety. All Team Members are responsible for assisting with checks. Night periods will be added at a later phase once supervision is available. }\end{array}$} \\
\hline \multirow{4}{*}{ Date } & \multicolumn{4}{|c|}{ Morning 7a-1p } & \multicolumn{4}{|c|}{ Afternoon 1p-7p } \\
\hline & Supervisor Initial & Staff Observed & Time Observed & \begin{tabular}{|l} 
Required \\
Teaching \\
\end{tabular} & Supervisor Initial & Staff Observed & Time Observed & $\begin{array}{l}\text { Required } \\
\text { Teaching }\end{array}$ \\
\hline & & & & $\mathrm{Y} / \mathrm{N}$ & & & & $\mathrm{Y} / \mathrm{N}$ \\
\hline & & & & $\mathrm{Y} / \mathrm{N}$ & & & & $\mathrm{Y} / \mathrm{N}$ \\
\hline
\end{tabular}




\section{APPENDIX 2 \\ SAMPLE OF A COMPLETED SUPERVISORY CHECK SENT IN EMAL}

\begin{tabular}{|c|c|c|c|c|c|c|c|c|c|}
\hline \multicolumn{10}{|c|}{ Completed Supervisory Checks } \\
\hline Date & $4 / 1 / 2018$ & $4 / 2 / 2018$ & $4 / 3 / 2018$ & $4 / 4 / 2018$ & $4 / 5 / 2018$ & $4 / 6 / 2018$ & $4 / 7 / 2018$ & \multirow{2}{*}{$\begin{array}{l}\text { \% of all Periods } \\
\text { completed }\end{array}$} & \multirow{2}{*}{$85.7 \%$} \\
\hline Week 43 & Sunday & Monday & Tuesday & Wednesday & Thursday & Friday & Saturday & & \\
\hline$\underset{7 a-1 p}{\text { Morning }}$ & Fred & & Fran & Fred & Frank & Fin & Fabio & \multicolumn{2}{|c|}{ Completed Most Checks } \\
\hline $\begin{array}{l}\text { Afternoon } \\
1 \mathrm{p}-7 \mathrm{p}\end{array}$ & Francesca & & Fin & Fred & Fred & Fran & Frankie & \multicolumn{2}{|c|}{ Fred } \\
\hline
\end{tabular}

\section{APPENDIX 3 \\ STEPS ON HOW TO HAVE A MEANINGFUL AND POSITIVE INTERACTION}

The steps on how to have a meaningful and positive interaction were taken from Stoutimore (2005) and were revised and taught as:

1. Move within arm's reach: Moving near the individual demonstrates caring and attention. It makes the interaction more personal.

2. Use touch appropriate to the situation: Touch can have a lot of impact-it is a basic human need. NOTE: use touch only if the individual is comfortable being touched-know your client.

3. Show caring facial expressions.

4. Be relaxed: Have relaxed posture with arms open while looking at the individual.

5. Use Caring tone of voice: Avoid sounding like a robot. $93 \%$ of what you say comes through in body language-BE GENUINE.

6. Ask open-ended positive questions: Ask questions that the individual is likely to answer and are not Yes/No questions. This shows interest in the individual, keeps the interaction going, and gives important information.

7. Use validation statements: Validation shows interest; it also demonstrates caring, attentiveness, and builds relationships. You show the individual that you "get where they are coming from."

8. Encourage: Acknowledge that the individual is doing or has done something to improve their situation. This helps connect the individual's behavior to the improvements that behavior has created. It demonstrates that you believe they can "do it" (or "do it again") to further create improvements and it shows that you are available to help.

9. Listen while the individual talks: This demonstrates caring, engagement in the interaction, and provides important information.

10. Avoid reacting to junk behavior: Avoid reacting to those things that are annoying but not harmful. Reacting to junk behavior may show that you "don't care." Keep talking as if the junk behavior never occurred.

11. Avoid coercion: Avoid disrespecting, shaming, or in any way "forcing" an interaction.

12. In the event that the individual is engaged in a group or activity, use steps 1-4 above. Notice the individual with gestures such as waves, salutes, pats on the back, etc. and upbeat facial expressions such as smiling to demonstrate that you notice that individual. 


\section{APPENDIX 4 \\ HOW TO COMPLETE SUPERVISORY CHECKS}

\section{The steps to observe and give feedback:}

1. Recognition: Observe for 10-minutes and recognize a staff member following successful positive interactions or for attempts to complete the task. Give specific praise and utilize the same steps above to ensure that the interaction is positive.

2. Give corrective feedback: When the interaction attempt does not meet expectations, then talk about how the staff member can improve performance to match expectations. This feedback should remain a positive experience not a tool to shame staff (see below).

3. Model: Once corrective feedback has been given, supervisors should then model a meaningful interaction. This means having a staff member follow along with the supervisor as the supervisor engages in meaningful interactions.

4. Request a demonstration: Once the supervisor has modeled a meaningful interaction request that the staff member demonstrate a sample interaction. Return to Step 1.

5. If no attempt was made to engage in meaningful interactions during observation, then gently tell the individual that you are going to assist them with the behavior. Utilize steps for Positive Feedback above to ensure that you are not shaming the staff member. Return to Step 3.

6. Record data on sheet: Once the staff member successfully demonstrates the meaningful interaction and has been positively recognized by the supervisor, the supervisor should record the evaluation on the data sheet, indicating that they did the review.

\section{APPENDIX 5 \\ THE NUMBER OF TOTAL CHALLENGING BEHAVIORS DURING BASELINE AND IMPLEMENTATION ACROSS SETTINGS}

\begin{tabular}{lll}
\hline Setting & $\begin{array}{l}\text { \# of Behavioral Incidents } \\
\text { During Baseline }\end{array}$ & $\begin{array}{l}\text { \# of Behavioral Incidents } \\
\text { During Implementation }\end{array}$ \\
\hline \hline HF1 & 349 & 166 \\
G01 & 117 & 48 \\
G02 & 45 & 28 \\
B08 & 138 & 54 \\
B09 & 83 & 51 \\
ISL 1 & 13 & 3 \\
ISL 2 & 31 & 2 \\
\hline
\end{tabular}




\begin{tabular}{|c|c|c|}
\hline THE NUMBER OF & $\begin{array}{r}\text { APPENI } \\
\text { IYSICAL ALTERCATI } \\
\text { IMPLEMENTATION }\end{array}$ & $\begin{array}{l}\text { X } 6 \\
\text { S WITH STAFF DURINC } \\
\text { ROSS SETTINGS }\end{array}$ \\
\hline Setting & $\begin{array}{l}\text { \# of Physical } \\
\text { Altercations with Staff } \\
\text { During Baseline }\end{array}$ & $\begin{array}{l}\text { \# of Physical Altercations } \\
\text { with Staff During } \\
\text { Implementation }\end{array}$ \\
\hline HF 1 & 183 & 63 \\
\hline G01 & 61 & 22 \\
\hline $\mathrm{G} 02$ & 15 & 5 \\
\hline B08 & 61 & 27 \\
\hline B09 & 49 & 26 \\
\hline ISL 1 & 1 & 0 \\
\hline ISL 2 & 1 & 0 \\
\hline
\end{tabular}

APPENDIX 7

THE AMOUNT OF TIME DURING BASELINE \& IMPLEMENTATION AS CONTINUOUS WEEKS ACROSS SETTINGS

\begin{tabular}{lll}
\hline \hline Setting & $\begin{array}{l}\text { \# of weeks during } \\
\text { baseline }\end{array}$ & $\begin{array}{l}\text { \# of weeks during } \\
\text { implementation }\end{array}$ \\
\hline \hline HF1 & 104 & 104 \\
G01 & 47 & 47 \\
G02 & 30 & 30 \\
B08 & 29 & 29 \\
B09 & 28 & 28 \\
ISL 1 & 32 & 32 \\
ISL 2 & 30 & 30
\end{tabular}

